\title{
Response to Goal Management Training in Veterans with blast-related mild traumatic brain injury
}

\author{
J. Kay Waid-Ebbs, PhD, BCBA-D; ${ }^{*}$ Janis Daly, PhD; ${ }^{1-2}$ Samuel S. Wu, PhD; ${ }^{3}$ W. Keith Berg, PhD; ${ }^{4}$ Russell M. \\ Bauer, PhD; ${ }^{1,5}$ William M. Perlstein, PhD; ${ }^{1,5}$ Bruce Crosson, PhD ${ }^{1,5-6}$ \\ ${ }^{1}$ Department of Veterans Affairs (VA), Rehabilitation Research and Development, Brain Rehabilitation Research Center, \\ Gainesville, FL; Departments of ${ }^{2}$ Physical Therapy, Neurology, and Biomedical Engineering, ${ }^{3}$ Statistics, ${ }^{4}$ Psychology, \\ and ${ }^{5}$ Clinical and Health Psychology, University of Florida, Gainesville, FL; ${ }^{6}$ Department of Neurology, Emory Uni- \\ versity, Atlanta, GA; Department of Psychology, Georgia State University, Atlanta, GA; and VA, Rehabilitation \\ Research and Development, Center for Excellence for Visual and Neurocognitive Rehabilitation, Atlanta, GA
}

\begin{abstract}
Veterans with blast-related mild traumatic brain injury (TBI) experience cognitive deficits that interfere with functional activities. Goal Management Training (GMT), which is a metacognitive intervention, offers an executive function rehabilitation approach that draws upon theories concerning goal processing and sustained attention. GMT has received empirical support in studies of patients with TBI but has not been tested in Veterans with blast-related mild TBI. GMT was modified from 7 weekly to 10 biweekly sessions. Participants included six combat Veterans who reported multiple blast exposures resulting in symptoms consistent with mild TBI. Group analysis showed a significant improvement in measures of executive function derived from performance on the computerized Tower of London. There were no significant changes on self/informant questionnaires of executive function, indicating a lack of generalization of improvement from the clinic to everyday activities. Overall, while the data indicate efficacy of GMT in the rehabilitation of combat Veterans with executive function deficits because of blast-related mild TBI, enhancement of generalization is needed.
\end{abstract}

Key words: blast injury, cognitive rehabilitation, combat Veterans, concussion, executive function, intervention, Operation Enduring Freedom, Operation Iraqi Freedom, Operation New Dawn, traumatic brain injury.

\section{INTRODUCTION}

The frequent use of improvised explosive devices in the Operation Iraqi Freedom/Operation Enduring Freedom/Operation New Dawn (OIF/OEF/OND) wars is one factor that has resulted in an increase in the prevalence of combat-related mild traumatic brain injuries (mTBIs) in returning military Veterans.

Combat Veterans diagnosed with mTBI commonly have deficits in attention, memory, and executive function [1]. These deficits interfere with everyday activities

Abbreviations: BRIEF-A = Behavior Rating Index of Executive Function-Adult Version, $\mathrm{cTOL}=$ computerized Tower of London, D-KEFS = Delis-Kaplan Executive Function System, GEC = global executive composite, GMT = Goal Management Training, $\mathrm{mTBI}$ = mild traumatic brain injury, OIF/OEF/OND = Operation Iraqi Freedom/Operation Enduring Freedom/Operation New Dawn, OM = optimal move, $\mathrm{PTSD}=$ posttraumatic stress disorder, $\mathrm{SD}=$ standard deviation, $\mathrm{TBI}=$ traumatic brain injury, TOL $=$ Tower of London.

*Address all correspondence to J. Kay Waid-Ebbs, PhD, BCBA-D; Mail Code 151-A, Malcom Randall VAMC, 1601 SW Archer Rd, Gainesville, FL 32607; 352-376-1611, ext 5224. Email: Julia.Waid-Ebbs@va.gov

http://dx.doi.org/10.1682/JRRD.2013.12.0266 
such as planning meals, paying bills, keeping a schedule, and making decisions. In fact, disorganization as a result of executive dysfunction is the most common complaint in individuals with traumatic brain injury (TBI) [2]. Executive deficits may be expected to lead to functional deficits in a broad range of cognitive, emotional, and social skills [3], though more data are needed about how laboratory-based measures of executive dysfunction map onto real-life skills [4].

Several evidence-based treatments of executive dysfunction are currently available [5], with metacognitive training most often recommended [5-7]. Metacognition refers to self-regulation, awareness of one's psychological state, and online implementation of compensatory strategies when needed to alleviate a real-life functional deficit. One evidence-based metacognitive intervention, Goal Management Training (GMT) [8], teaches selfregulation to individuals with brain injury by identifying "slips" (errors in processing) and implementing strategies to reduce those slips. Strategies are taught in a step-bystep fashion and practiced using simulated tasks within sessions and at home. Key strategies in GMT include "stop-what am I doing?," "define the goal," "list the steps," "learn the steps" then "check—am I doing what I planned?” [9].

GMT is based on Duncan et al.'s theory of goal neglect [10-11], in which a task is understood and remembered but does not occur. Levine et al. refer to this goal neglect as "slips" [9]. In order to achieve a goal, several steps need to be coordinated. First, the difference between the current state and the desired state must be detected. Second, there must be formulation of the steps needed to reach that desired state. Third, the desired state must be kept in mind while resisting distractions. Fourth, the barriers that occur along the way must be overcome until finally the goal is achieved. Once the goal is achieved, the result must be evaluated. Duncan et al. refer to the inability to keep the goal in mind while engaged in problem solving as "goal neglect" [10-11]. After a brain injury, intention and action can become dissociated; individuals with frontal lobe damage may be able to verbalize the appropriate action to take, but may not implement that action [12]. A new plan requires the ability to maintain intentions as well as the execution path of those intentions [9].

Maintaining intention is also referred to as selfregulation. Although self-regulation is less important for well-learned, automatic activities and routines, it is vital in new activities that require inhibition of an overlearned plan so that a new problem-solving strategy can be developed. Impairments in inhibitory processes are prominent in Veterans with blast-related mTBI [13]. Therefore, a GMT strategy may benefit Veterans with persistent executive dysfunction because of blast-related mTBI if that GMT strategy directly addresses inhibitory failure as a barrier to goal attainment.

A recent systematic review of studies that administered GMT, either alone or in combination with other therapies, concluded that there was a lack of evidence to support GMT as a stand-alone therapy for acquired brain injury [14]. Of the studies reviewed, eight used GMT alone, but only one provided scientific rigor to support the effect of GMT [15]. However, only four of the patients included in this study were diagnosed with TBI, with no report of their severity level [15]. Yet, GMT has been shown to be efficacious in other populations including elderly and abstinent polysubstance abusers [16-18]. Levine et al. speculated from their initial study that patients with mTBI might benefit from GMT more than patients with severe TBI because of their ability to better utilize learned strategies [9]. However, to date GMT has not been vigorously examined in mTBI. Six of the reviewed GMT studies included participants diagnosed with TBI, but only four mentioned the inclusion of mTBI participants [9,15,19-20]. Even then, severity criteria were not presented, nor were outcomes indicated for each severity level, which prevents conclusions regarding the effect of GMT in mTBI. Further research is needed to determine whether GMT is efficacious in mTBI. Therefore, the purpose of this study was to test the effect of GMT on Veterans with executive function deficits following repeated blast-related mTBI.

\section{METHODS}

\section{Participants}

Ten OIF/OEF/ONF Veterans reporting cognitive deficits were recruited from the North Florida/South Georgia Veterans Health System, Speech Services. Participants were competent English-speaking Veterans aged 18 to $55 \mathrm{yr}$ who met the following inclusion criteria: (1) diagnosis of repeated mTBI [21] as a result of blast exposure at least 4 mo prior to study inclusion, (2) impairment of executive function as indicated by a score 1.5 standard deviations or more below the mean on any subtest of 
the Delis-Kaplan Executive Function System (D-KEFS) battery during screening, (3) score of 90 or higher on the National Adult Reading Test [22], and (4) a score of at least 45 on trial 1 or 2 of the Test of Memory Malingering [18,23-25]. Potential participants were excluded if they (1) had a formal diagnosis of learning disability in the developmental period, (2) had a psychiatric diagnosis with hospitalization, (3) reported alcohol or substance abuse in the past year, (4) were involved in litigation, (5) had a change of medication within the past month that could affect cognition, (6) were enrolled in other cognitive therapy, or (7) did not have an informant to attend the first session and report on their functioning. The informants were at least $18 \mathrm{yr}$ of age, competent English speaking, and willing to sign consent.

Of the 10 participants enrolled in this study, 6 completed all sessions. Four participants dropped out of the study prior to treatment: two dropped out because of employment opportunities and the other two dropped out without giving a reason. Demographics of the six participants participating in treatment are listed in Table 1. They had mean age of $31 \mathrm{yr}$ (standard deviation [SD] =
$6.7 \mathrm{yr}$ ) and average years since injury of $2.8 \mathrm{yr}(\mathrm{SD}=$ $1.3 \mathrm{yr}$ ). Each Veteran identified an informant who observed the Veteran's everyday activities at least twice a week. Informants selected were parents $(n=2)$, a sister $(n=1)$, a girlfriend $(n=1)$, and spouses $(n=2)$.

The participants in this study each had two or more concussions resulting from blast exposures. All six participants had a diagnosis of chronic posttraumatic stress disorder (PTSD) in their medical record, and four had a PTSD Checklist-Military Version score administered at screening indicating PTSD. Two participants had a Beck Depression Inventory-Second Edition score administered at screening indicating severe depression. Intelligence of all six participants was estimated at normal to superior using the North American Adult Reading Test.

\section{Intervention}

GMT is an interactive psychoeducational intervention using seven PowerPoint (Microsoft; Redmond, Washington) modules for guided presentation of information, group interaction, and practice of complex tasks that was provided by Levine et al. [9]. We modified the 7 weekly

Table 1.

Demographics.

\begin{tabular}{|c|c|c|c|c|c|c|}
\hline Patient & Age/Race/Sex & Concussions & $\begin{array}{c}\text { PCL-M ( } \geq 50= \\
\text { PTSD)/BDI-II } \\
\text { ( } \geq 29=\text { severe } \\
\text { depression) }\end{array}$ & $\begin{array}{c}\text { Time from Most } \\
\text { Recent Injury, } \\
\text { Service, } \\
\text { Deployment }\end{array}$ & $\begin{array}{c}\text { NAART- } \\
\text { Estimated FSIQ }\end{array}$ & $\begin{array}{c}\text { Homework } \\
\text { Completion (\%) }\end{array}$ \\
\hline 1 & 33/W/M & $\begin{array}{l}\text { Total }=2, \\
2 \text { grade III }\end{array}$ & $75^{*} / 39^{*}$ & $\begin{array}{l}2 \text { yr, Army, } \\
\text { Afghanistan }\end{array}$ & 109 & 40 \\
\hline 2 & 27/W/M & $\begin{array}{l}\text { Total }=3, \\
2 \text { grade I, } \\
1 \text { grade III }\end{array}$ & $59^{*} / 43^{*}$ & $\begin{array}{l}5 \text { yr, Army, Iraq, } \\
2 \text { deployments }\end{array}$ & 113 & 61 \\
\hline 3 & 25/W/F & $\begin{array}{l}\text { Total = } 3, \\
1 \text { grade II, } \\
2 \text { grade III }\end{array}$ & $43 / 12$ & 2 yr, Army, Iraq & 101 & 19 \\
\hline 4 & 38/AA/F & $\begin{array}{l}\text { Total }=3, \\
2 \text { grade III, } \\
1 \text { grade II }\end{array}$ & $50 * / 19$ & 2 yr, Army, Iraq & 111 & 11 \\
\hline 5 & 40/W/M & $\begin{array}{l}\text { Total }=2, \\
2 \text { grade I }\end{array}$ & $41 / 28$ & 5 yr, Army, Iraq & 111 & 28 \\
\hline 6 & 25/W/M & $\begin{array}{l}\text { Total }=4, \\
1 \text { grade III, } \\
3 \text { grade I }\end{array}$ & $66^{*} / 25$ & $\begin{array}{l}4 \text { yr, Marines, } \\
\text { Iraq, } 3 \text { deploy- } \\
\text { ments }\end{array}$ & 108 & 67 \\
\hline
\end{tabular}

\footnotetext{
*Scores reflect severe depression or PTSD.
}

AA = African American, BDI-II = Beck Depression Inventory-Second Edition, F = female, FSIQ = Full Scale Intelligence Quotient, $\mathrm{M}=$ male, NAART $=$ North American Adult Reading Test, PCL-M = PTSD Checklist-Military Version, PTSD = posttraumatic stress disorder, $\mathrm{W}=$ white. 
PowerPoint modules by increasing the sessions to 10 and presenting biweekly sessions. The three additional sessions included an initial educational session and splitting sessions five and six into two sessions each. The split sessions allowed for time to practice complex tasks that are included in GMT and to discuss homework assignments.

The first session was an added educational presentation for the participants and their informants. The presentation described the mechanisms of blast and PTSD on the brain, resulting symptoms, typical recovery from concussion, recommended treatments, and what to expect during GMT. During the remaining nine sessions, participants were taught a five-stage strategy consisting of increasing awareness and proficiency in the following actions: "stop—what am I doing?," "define the goal," "list the steps," "learn the steps," then "check-am I doing what I planned?” The strategy was then incorporated into simulated tasks practiced during the session as well as in functional tasks practiced at home. Tasks during GMT training include exercises such as (1) clapping to words while inhibiting clapping to a predesignated target word, (2) card sorting, (3) mindfulness exercises, (4) decision-making and planning in order to complete five activities within a 4 min time span, (5) catalog task, and (6) book keeping task. The exercises started with relatively easy tasks and progress to more complex tasks. The participants' strengths and weaknesses were discussed. Improvements were identified and reinforced as they learned more efficient planning and problem solving. The participants discussed utilization of the strategies in their daily lives and reviewed their progress at each session. The informants were asked to observe homework assignments weekly and report on whether the participant had any difficulty completing their homework.

\section{Treatment Design and Data Acquisition}

An A/B design [26] was used for this study. Six Veterans participated in five weekly baseline probes prior to GMT and in five weekly treatment probes during the GMT intervention, as depicted in Figure 1. An additional probe was conducted 1 mo after treatment concluded. A questionnaire was administered prior to baseline, after intervention, and 1 mo after treatment was concluded.

\section{Measures of Executive Function}

\section{Weekly Probes}

GMT is a metacognitive training with emphasis on planning prior to engaging in a complex task. Therefore, the Tower of London (TOL), a primary measure that captures the planning and problem solving of a multistep task, was selected. The computerized TOL (cTOL) offers unique problems for each session, thus reducing the potential for practice effects associated with a repeated measure. A similar version of the TOL, the TOL ${ }^{\mathrm{DX}}$ (TOL-Drexel University) demonstrated that the execution time is impaired in mTBI compared with controls [27]. Levine et al. demonstrated a significant change in the D-KEFS TOL subtest following GMT for a mixed neurological sample compared with a control group [15]. Thus, the TOL has been shown to be sensitive to mTBI and the effects of GMT.

The cTOL was administered for five weekly baseline probes, five weekly treatment probes, and a 1 mo followup probe (Figure 1). In the cTOL, the participant is shown a picture of a goal board above a move board (Figure 2) [28-29]. Each picture shows three balls of different colors arranged on three pegs, with the balls in a unique arrangement in each picture. Participants are instructed to rearrange the move board to match the goal board in as few moves as possible within a $60 \mathrm{~s}$ trial. Only one ball can be moved at a time, and a peg cannot be overloaded. The screen reports whether the response is correct or incorrect. Each set consists of 10 unique problems with a mixture of $4,5,6$, or 7 move problems. The same average difficulty level was established for each set based on global and specific problem parameters shown to affect the planning process [28,30-31]. Dependent variables included total time to complete the problem, planning (time before first move), and proportion of optimal moves (OMs) (toward the goal) to nonoptimal moves (away from the goal). The proportion of OM was calculated by the following formula (Equation 1):

$$
\mathrm{OM}=\frac{\text { moves toward goal }- \text { moves away from goal }}{\text { total moves }} .
$$

OMs varied from -1 (indicating that all moves were nonoptimal) to +1 (indicating that all moves were optimal). 


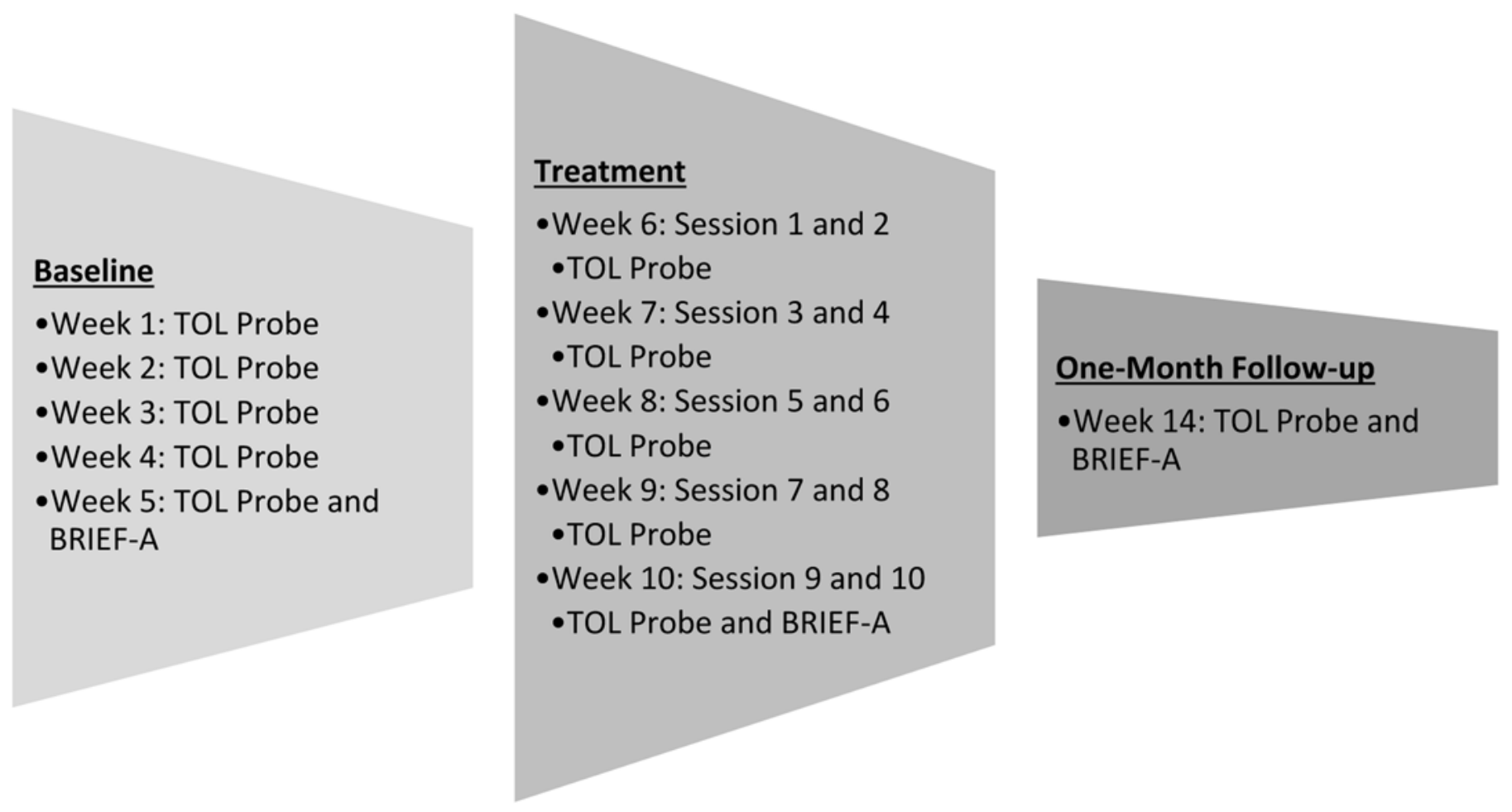

Figure 1.

Data acquisition schedule. BRIEF-A = Behavior Rating Inventory of Executive Functions-Adult Version, TOL $=$ Tower of London.

\section{Tower of London}

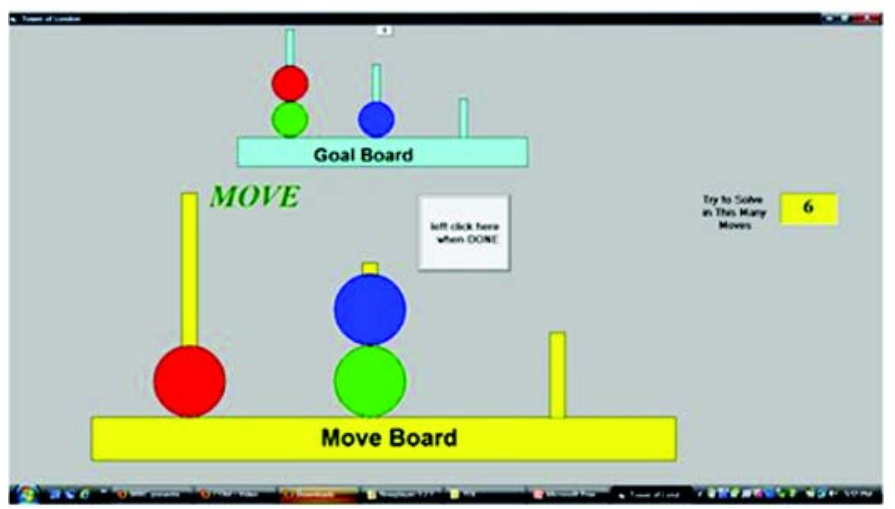

Figure 2.

Example of computerized Tower of London.

\section{Generalization Probe}

To determine whether GMT, which was conducted in the clinic, generalized [32] to everyday executive function behaviors in the home setting, a questionnaire called the Behavior Rating Inventory of Executive FunctionsAdult Version (BRIEF-A) was selected. The BRIEF-A is a self-report and proxy report questionnaire of behaviors suggestive of executive dysfunction [33]. The questionnaire consists of 75 statements about executive behaviors to which the respondent answers regarding how frequently the behavior is displayed ("often," "sometimes," or "never”). There are two index scores and a global executive composite (GEC) score. The Behavior Rating Index is a summary of five scales (Initiate, Working Memory, Plan/Organize, Task Monitor, and Organization of Materials), and the Metacognition Index is a summary of four scales (Inhibit, Shift, Emotional Control, and Self-Monitor).The GEC score is the sum of the two index scores. Reliability (Cronbach alpha) calculated on a mixed neurological sample ranged from 0.73 to 0.90 for the scales and 0.93 to 0.96 for the GEC scores [33]. Testretest reliability over 4 wk averaged 0.82 to 0.93 on the scales and 0.94 for GEC score [33]. The total BRIEF-A score shows high overlap $(r=+0.84)$ with the Dysexecutive Questionnaire [33]. Good item-level psychometrics have been demonstrated in a moderate/severe TBI sample with a Cronbach alpha of 0.94 and 0.96 for each of the index scores [34]. 


\section{Data Analysis}

To study the effect from baseline to treatment (acquisition) and treatment to 1 mo follow-up (maintenance), data were analyzed for six participants using a $t$-test for paired samples. Baseline performance was measured by averaging the scores for each of the cTOL measurestotal time, time to first move, and proportion of OMsacross the five baseline probes. Similarly, scores were averaged across the five probes conducted weekly during the 10 biweekly GMT training sessions to obtain a treatment score on each cTOL measure (Figure 1).

To provide confidence that improvement was not due to practice effects, we repeated the above analysis after removing the first baseline session. Performance during the first exposure to the cTOL might be slower as the participant learns how to perform the task [35]. Therefore, removing the first session would reduce the improvement boost following session 1 . In addition, regression analyses were performed to examine how the changes in cTOL were associated with the time since injury, the percentage of homework assignments turned in, and impairment in inhibition as measured by the D-KEFS subtest, Color Word Interference Test score.

\section{Generalization}

In secondary, exploratory analysis, both BRIEF-A index and subscale scores of Veterans and informants were analyzed to determine whether GMT improved executive function in everyday activities outside of the clinic. A $t$-test for paired samples was used to compare the baseline score to the metacognitive index score and each scale score.

\section{RESULTS}

In comparison of the mean baseline with mean treatment measures, there was a significant acquisition improvement according to the cTOL measures of total time and OMs (Table 2). Even with the first baseline session removed to control for potential practice effects, significant improvement was evident for total time and OM (Table 2). The measure of planning time did not show a significant improvement after treatment.

Impairment levels in inhibition, time since injury, and percentage of homework were examined for their association with response to treatment. Impairment of inhibition function was measured by the D-KEFS subtest, Color Word Interference Test, Condition 3 standard scale scores. A regression analysis indicated that for every point of impairment on the Color Word Interference Test, there was an associated 1.3 points improvement on the cTOL (95\% confidence interval: 0.2-2.4). Thus, patients with more impairment had a greater response to treatment. Time since injury and the percentage of homework assignments turned in were not predictive of changes.

Total time, planning time, and OMs of the cTOL did not significantly change from baseline to the 1 mo posttreatment probe because of high variability. From these findings, we infer that improvement in total time and OMs from treatment was not maintained at follow-up. Of the cTOL measures, only planning time did not demonstrate a significant improvement in acquisition or maintenance.

Table 2.

Paired $t$-test on six subjects with and without first session.

\begin{tabular}{|c|c|c|c|c|}
\hline Variable & Difference & $\begin{array}{c}\text { Mean } \\
\text { With/Without } \\
\text { First Session }\end{array}$ & $\begin{array}{c}t \text {-Value } \\
\text { With/Without } \\
\text { First Session }\end{array}$ & $\begin{array}{c}p \text {-Value } \\
\text { With/Without } \\
\text { First Session }\end{array}$ \\
\hline \multirow[t]{3}{*}{ Total Time } & Treatment-Baseline & $-6.21 /-4.76$ & $-3.12 /-2.76$ & $0.03 / 0.04$ \\
\hline & 1 mo Posttreatment-Baseline & -12.16 & -2.19 & 0.09 \\
\hline & 1 mo Posttreatment-Treatment & 1.64 & 0.74 & 0.50 \\
\hline \multirow[t]{2}{*}{ Planning Time } & Treatment-Baseline & $-1.14 /-0.60$ & $-1.160 /-0.734$ & $0.30 / 0.50$ \\
\hline & 1 mo Posttreatment-Treatment & -0.63 & -0.494 & 0.65 \\
\hline \multirow[t]{3}{*}{ Optimal Moves } & Treatment-Baseline & 0.06/0.06 & $3.28 / 2.93$ & $0.02 / 0.03$ \\
\hline & 1 mo Posttreatment-Baseline & 0.03 & 0.43 & 0.69 \\
\hline & 1 mo Posttreatment-Treatment & -0.06 & -2.38 & 0.08 \\
\hline
\end{tabular}


Generalization of treatment changes to everyday activities was not observed according to the BRIEF-A. According to responses from participants and their informants on the BRIEF-A scales or index scores, there was not a significant change from baseline to posttreatment (Table 3). The effect size (Cohen $d$-statistic) for Behavior Regulation Index was 0.42 for patients and 0.27 for caregivers; the Metacognition Index had an effect size of 0.08 for patients and 0.49 for caregivers. Nor was there a significant change between baseline and the 1 mo posttreatment measures (Table 4).

\section{DISCUSSION}

To our knowledge, this is the first report of the effect of GMT in Veterans with blast-related mTBI. While minor modifications were made to the frequency and number of GMT sessions, the treatment was essentially the same as the seven-session GMT manualized treatment used in Levine et al.'s study [15]. In this study, Veterans with cognitive impairment associated with blastrelated mTBI demonstrated improved performance in problem solving following GMT. Significant improve- ments in total time and OMs were found between five baseline and five treatment cTOL probes.

Similar to our results for our mTBI group, others found that the GMT was effective in mixed neurological samples and other impaired patient diagnostic categories $[15,36]$. For example, Levine et al. found significant improvement for the GMT group on the achievement score of the D-KEFS subtest, TOL [15] and Spikman et al. found a significant improvement in total time on the Shallice, 1982 version of the TOL for their treatment that included GMT as a component for those with neurological injury (mostly stroke) [36]. Neither study demonstrated a significant difference between the GMT group and the comparative treatment group. Nor did Schweitzer et al. report a significant improvement in their case study which used the total achievement score of the D-KEFS subtest TOL [37].

However, it should be noted that different versions of the TOL make study comparisons difficult [38]. For example, the D-KEFS subtest TOL differs from the cTOL in a few key aspects. First, the D-KEFS TOL has five blue discs versus three balls of different colors; second, the total achievement score is the correct number of moves within the time limit; in the current study, we used an OMs Index, total time, and planning time. Further, the

Table 3.

Behavior Rating Inventory of Executive Function-Adult Version patient/informant baseline to posttreatment.

\begin{tabular}{|c|c|c|c|c|c|c|c|c|}
\hline \multirow{2}{*}{ Variable } & \multicolumn{4}{|c|}{ Patient } & \multicolumn{4}{|c|}{ Informant } \\
\hline & $\begin{array}{c}\text { Difference } \\
\text { Pre-Post Mean }\end{array}$ & $\begin{array}{l}\text { Standard } \\
\text { Deviation }\end{array}$ & $t$-Value & $p$-Value & $\begin{array}{c}\text { Difference } \\
\text { Pre-Post Mean }\end{array}$ & $\begin{array}{l}\text { Standard } \\
\text { Deviation }\end{array}$ & t-Value & $p$-Value \\
\hline $\begin{array}{l}\text { Behavioral Regu- } \\
\text { lation Index }\end{array}$ & -2.50 & 5.96 & -1.028 & 0.35 & -2.50 & 9.12 & -0.67 & 0.53 \\
\hline Inhibit & -3.33 & -4.68 & -1.746 & 0.14 & -4.17 & 11.96 & -0.85 & 0.43 \\
\hline Shift & -5.67 & 6.71 & -2.068 & 0.09 & -8.33 & 9.69 & -2.11 & 0.09 \\
\hline Emotional Control & 0.50 & 5.09 & 0.241 & 0.82 & -1.33 & 4.97 & -0.66 & 0.54 \\
\hline Self-Monitor & -0.67 & 10.52 & -0.155 & 0.88 & -1.50 & 13.62 & -0.27 & 0.80 \\
\hline $\begin{array}{l}\text { Metacognitive } \\
\text { Index }\end{array}$ & -0.67 & 8.34 & -0.196 & 0.85 & -4.50 & 9.23 & -1.20 & 0.29 \\
\hline Initiate & 0.67 & 10.60 & 0.154 & 0.88 & -8.67 & 10.05 & -2.11 & 0.09 \\
\hline Working Memory & -1.00 & 8.56 & -0.286 & 0.79 & -2.00 & 6.48 & -0.76 & 0.48 \\
\hline Plan/Organize & -2.50 & 8.55 & -0.716 & 0.51 & -0.17 & 11.27 & -0.36 & 0.97 \\
\hline Task Monitor & -2.33 & 15.20 & -0.376 & 0.72 & -6.00 & 13.99 & -1.05 & 0.34 \\
\hline Organize Material & 3.17 & 8.23 & 0.942 & 0.39 & -5.50 & 15.86 & -8.50 & 0.43 \\
\hline $\begin{array}{l}\text { Global Executive } \\
\text { Composite }\end{array}$ & -1.83 & 7.36 & -0.610 & 0.57 & -4.50 & 3.69 & -1.22 & 0.28 \\
\hline
\end{tabular}


JRRD, Volume 51, Number 10, 2014

Table 4.4

Behavior Rating Inventory of Executive Functions-Adult Version patient/informant baseline to 1 mo follow-up.

\begin{tabular}{|c|c|c|c|c|c|c|c|c|}
\hline \multirow[b]{2}{*}{ Variable } & \multicolumn{4}{|c|}{ Patient } & \multicolumn{4}{|c|}{ Informant } \\
\hline & $\begin{array}{c}\text { Difference } \\
\text { Pre-Post Mean }\end{array}$ & $\begin{array}{l}\text { Standard } \\
\text { Deviation }\end{array}$ & t-Value & $p$-Value & $\begin{array}{c}\text { Difference } \\
\text { Pre-Post } \\
\text { Mean }\end{array}$ & $\begin{array}{l}\text { Standard } \\
\text { Deviation }\end{array}$ & t-Value & $p$-Value \\
\hline $\begin{array}{l}\text { Behavioral Regu- } \\
\text { lation Index }\end{array}$ & -5.00 & 7.38 & -1.51 & 0.20 & 2.00 & 9.76 & 0.41 & 0.71 \\
\hline Inhibit & -3.20 & 7.50 & -0.95 & 0.39 & 2.75 & 13.57 & 0.41 & 0.71 \\
\hline Shift & -4.40 & 5.37 & -1.83 & 0.14 & -3.25 & 15.95 & 0.41 & 0.71 \\
\hline Emotional Control & -1.80 & 7.19 & -0.56 & 0.61 & 1.25 & 8.54 & 0.29 & 0.79 \\
\hline Self-Monitor & -8.40 & 15.18 & -1.24 & 0.28 & 1.00 & 16.75 & 0.12 & 0.91 \\
\hline $\begin{array}{l}\text { Metacognitive } \\
\text { Index }\end{array}$ & -3.40 & 9.53 & -0.08 & 0.47 & 5.25 & 10.05 & 1.05 & 0.37 \\
\hline Initiate & 2.40 & 8.99 & 0.60 & 0.58 & 1.75 & 13.57 & 0.26 & 0.81 \\
\hline Working Memory & -4.80 & 10.45 & -1.03 & 0.36 & 3.25 & 16.92 & 0.38 & 0.73 \\
\hline Plan/Organize & -10.00 & 12.00 & -1.86 & 0.14 & 8.25 & 9.64 & 1.71 & 0.19 \\
\hline Task Monitor & -6.60 & 13.15 & -1.12 & 0.32 & 1.75 & 6.45 & 0.54 & 0.63 \\
\hline Organize Material & 4.00 & 8.97 & 1.00 & 0.38 & 4.00 & 9.20 & 0.87 & 0.45 \\
\hline $\begin{array}{l}\text { Global Executive } \\
\text { Composite }\end{array}$ & -5.40 & 10.53 & -1.15 & 0.32 & 3.75 & 11.62 & 0.65 & 0.56 \\
\hline
\end{tabular}

computerized format of the TOL used in the current study might differentially affect the performance compared with the other versions of the TOL. This occurred in the case of the Wisconsin Card Sorting Test for the computerized version, where greater variance was observed on the computerized version and resulted in an increase of scores misclassified as impaired in comparison to the manual version [39]. However, in a group of individuals with autism spectrum disorder, comparison of the wooden device and a computerized version of the TOL showed no difference in performance [40]. Advantages of the cTOL include its standardization and ease and reliability in scoring the task.

One variable that did not change in response to treatment was "time to first move," which measures planning time. The majority of subjects improved their efficiency in solving the problems by decreasing the amount of time to complete problems with less moves. Yet, the time to plan (time to first move) did not significantly decrease. Others have also noted that time to first move may not be a sensitive measure of planning [41-42].

As in other studies of GMT, our study showed that there was not generalization of planning and organizing skills taught in GMT, according to measures of daily activities reports of either the participant or the informant [9,15,19-20,43-44]. Only Schweitzer et al.'s study reported lessened complaints from the spouse about executive dys- function complaints [37]. Others have concluded that measurements at the activity and participation level (such as functional questionnaires) are less sensitive to change than measurements at the impairment level (such as neuropsychological measures) and that it may take longer for the achievement of new cognitive skills to change self-perception [45-46]. While GMT does use a multicontext approach [47] for transfer of training, sufficient practice to achieve mastery and generalization is lacking. In our GMT, several homework sessions are assigned to practice self-monitoring and using the strategies of "stop," "state," and "split" in simulated complex tasks as well as one task in the home identified by the participant. In our study, participants reported that they were using the strategies in their everyday activities, but in reality homework assignments were either incomplete or not turned in. Most participants failed to complete more than half of the homework assignments. There were some instances in which participants were observed completing self-monitor forms and functional task descriptions in the waiting room before the next session, regardless of the fact that the monitoring forms were designed to assist in reminding them in the moment at home to utilize their new strategies. Therefore, the lack of in-home practice may have contributed to a lack of improvement on daily activities as measured by the BRIEF-A. In any event, the absence of generalization needs to be addressed in future studies of GMT. 
GMT required a 3 mo commitment, which some might consider a long commitment. However, participants who completed this intervention reported that they were inspired by participating in the group and hearing experiences from other members. In addition, some reported that hearing that others were struggling with the same issues made them feel more "normal." Positive family interactions were reported as a result of including their significant others in education and reporting on the participant's executive function. The six participants who completed the study reported that overall, GMT was helpful in that they had learned the strategy of impulse control to "stop and think" before engaging in a complex task, thereby providing them the time to consider the implications of actions and better plan action steps.

The improvements in the TOL as a result of GMT are promising. Yet, there are limitations in our study that need to be considered. First, the sample size is small. Second, improvements from the intervention were not validated by comparison to a control group. Third, blastrelated mTBI is determined by self-report. Fourth, there is controversy regarding whether cognitive impairments can be attributed to mTBI years after the injury $[1,48]$ or whether cognitive impairments are strictly due to comorbidities such as PTSD and depression. In our work, four subjects had PTSD; considering this controversy, our results for GMT may have produced their effect on symptomatology from the combination of mTBI and comorbidities, or comorbidities alone.

In a recent review of GMT, Krasny-Pacini et al. stated that there is insufficient evidence to support GMT as a single intervention [14]. And there is limited to modest evidence for the effectiveness of cognitive rehabilitation training for TBI in general [49]. Despite the current state of the literature, a number of studies and sources continue to recommend metacognitive training and GMT, in particular, as the theory-based treatment of choice for executive function deficits in TBI [7-6]. Our study extends the current literature by providing further but limited support for use of GMT and a demonstration of the feasibility of GMT in not only participants with mTBI but also in individuals with military blast-related mTBI. Kennedy et al. expressed the need for such studies to determine best practices for this unique population [5]. To our knowledge, this is the first published study of an executive function intervention for Veterans diagnosed with blast-related mTBI.

Research is needed to further study the elements of GMT and its effect in a larger sample of Veterans with executive function deficits as a result of mTBI. Determining the "active ingredients" in GMT will enable a more targeted intervention or identify additional training that could enhance GMT, such as training to transfer, attention training [50], or problem-solving training [36]. Additional training could be incorporated before or after GMT or integrated within GMT by engaging in complex tasks in the community utilizing GMT strategies learned during the sessions. Based on our experience, we suggest that integrating problem-solving training in the completion of complex tasks in the home may improve generalization and use of the GMT strategies. Our study showed that participants with more impairment were more likely to benefit from GMT. Future participant selection for GMT may be guided by identifying characteristics, such as impairment level, that would predict improvement from GMT.

Selection of outcome measures for executive function interventions is challenging. Krasny-Pacini et al. [14] and Lewis et al. [4] described the lack of ecological validity in many executive function measures and the limitations of measures that are more functionally based. Functional measures often lack standardization, norms, and adequate test-retest reliability. In addition, measures must be difficult enough to capture the ability of the sample. For example, the Revised-Strategy Application Task and Hotel Task had significant ceiling effects and did not capture improvement [37]. Currently, we are testing a Smartphone app that will monitor completion of complex tasks selected by the participants. The Smartphone app will measure time to completion and whether the participant is on task at variable intervals. In addition to everyday functional measures, we are examining the use of standardized tests, such as the Stop Signal Task [51-52] and the EXAMINER test battery [53] from the National Institutes of Health toolbox.

\section{CONCLUSIONS}

Our study extends the current literature by providing further but limited support for the use of GMT for metacognitive training for patients with mTBI and demonstrates its feasibility among individuals with military blast-related mTBI. 


\section{ACKNOWLEDGMENTS}

\section{Author Contributions:}

Study concept and design: B. Crosson, J. K. Waid-Ebbs.

Acquisition of data: J. K. Waid-Ebbs.

Analysis and interpretation of data: S. S. Wu, J. K. Waid-Ebbs,

J. Daly, W. K. Berg.

Drafting of manuscript: J. K. Waid-Ebbs, J. Daly.

Critical revision of manuscript for important intellectual content:

B. Crosson, S. S. Wu, W. K. Berg, W. M. Perlstein, R. M. Bauer,

J. Daly.

Statistical analysis: S. S. Wu, J. K. Waid-Ebbs, W. K. Berg.

Obtained funding: B. Crosson, J. K. Waid-Ebbs.

Administrative, technical, or material support: W. K. Berg, B. Crosson, J. Daly, W. M. Perlstein.

Study supervision: B. Crosson, J. Daly, W. M. Perlstein.

Financial Disclosures: The authors have declared that no competing interests exist.

Funding/Support: This material was based on work supported by the Department of Veterans Affairs, Veterans Health Administration, Rehabilitation Research and Development Service (award B6700M),

J. Kay Waid-Ebbs, Health Scientist, Brain Rehabilitation Research

Center of Excellence, Gainesville, Florida.

Additional Contributions: Special thanks go to Brian Levine, $\mathrm{PhD}$, for providing the GMT intervention materials and training and to Leslie Gonzalez-Rothi, PhD, and Nan Musson, MA, for their advice, encouragement, and recruitment of participants.

Institutional Review: This research was conducted in compliance with all applicable Federal regulations governing the protection of human subjects in research and approved by the University of Florida Institutional Review Board (Protocol No. 108-09).

Participant Follow-Up: The authors plan to inform participants of study publication.

\section{REFERENCES}

1. Vasterling JJ, Verfaellie M, Sullivan KD. Mild traumatic brain injury and posttraumatic stress disorder in returning veterans: Perspectives from cognitive neuroscience. Clin Psychol Rev. 2009;29(8):674-84. [PMID:19744760] http://dx.doi.org/10.1016/j.cpr.2009.08.004

2. Sohlberg MM, Mateer CA. Cognitive rehabilitation: An integrative neuropsychological approach. New York (NY): Guilford Press; 2001.

3. Lezak M, Howieson D, Loring D. Neuropsychological assessment. 4th ed. Oxford (UK): Oxford University Press; 2004.

4. Lewis MW, Babbage DR, Leathem JM. Assessing executive performance during cognitive rehabilitation. Neuropsychol Rehabil. 2011;21(2):145-63. [PMID:21229458] http://dx.doi.org/10.1080/09602011.2010.543867

5. Kennedy MR, Coelho C, Turkstra L, Ylvisaker M, Moore Sohlberg M, Yorkston K, Chiou HH, Kan PF. Intervention for executive functions after traumatic brain injury: A systematic review, meta-analysis and clinical recommendations. Neuropsychol Rehabil. 2008;18(3):257-99.

[PMID:18569745]

http://dx.doi.org/10.1080/09602010701748644

6. Cicerone KD, Langenbahn DM, Braden C, Malec JF, Kalmar K, Fraas M, Felicetti T, Laatsch L, Harley JP, Bergquist T, Azulay J, Cantor J, Ashman T. Evidencebased cognitive rehabilitation: Updated review of the literature from 2003 through 2008. Arch Phys Med Rehabil. 2011;92(4):519-30. [PMID:21440699]

http://dx.doi.org/10.1016/j.apmr.2010.11.015

7. Helmick K; Members of Consensus Conference. Cognitive rehabilitation for military personnel with mild traumatic brain injury and chronic post-concussional disorder: Results of April 2009 consensus conference. NeuroRehabilitation. 2010;26(3):239-55. [PMID:20448314]

8. Robertson I. Goal management training: A clinical manual. Cambridge (UK): PsyConsult; 1996.

9. Levine B, Robertson IH, Clare L, Carter G, Hong J, Wilson BA, Duncan J, Stuss DT. Rehabilitation of executive functioning: An experimental-clinical validation of goal management training. J Int Neuropsychol Soc. 2000;6(3):299312. [PMID:10824502] http://dx.doi.org/10.1017/S1355617700633052

10. Duncan J, Emslie H, Williams P, Johnson R, Freer C. Intelligence and the frontal lobe: The organization of goaldirected behavior. Cognit Psychol. 1996;30(3):257-303. [PMID:8660786] http://dx.doi.org/10.1006/cogp.1996.0008

11. Duncan J. Disorganization of behavior after frontal lobe damage. Cogn Neuropsychol. 1986;3:271-90. http://dx.doi.org/10.1080/02643298608253360

12. Luria A. Human brain and psychological processes. New York (NY): Harper and Row; 1966.

13. Swick D, Honzel N, Larsen J, Ashley V, Justus T. Impaired response inhibition in veterans with post-traumatic stress disorder and mild traumatic brain injury. J Int Neuropsychol Soc. 2012;18(5):917-26. [PMID:22595028] http://dx.doi.org/10.1017/S1355617712000458

14. Krasny-Pacini A, Chevignard M, Evans J. Goal Management Training for rehabilitation of executive functions: A systematic review of effectiveness in patients with acquired brain injury. Disabil Rehabil. 2014;36(2):105-16. [PMID:23597002]

15. Levine B, Schweizer TA, O’Connor C, Turner G, Gillingham S, Stuss DT, Manly T, Robertson IH. Rehabilitation of executive functioning in patients with frontal lobe brain damage with goal management training. Front Hum Neurosci. 2011;5:9. [PMID:21369362]

http://dx.doi.org/10.3389/fnhum.2011.00009 
16. van Hooren SA, Valentijn SA, Bosma H, Ponds RW, van Boxtel MP, Levine B, Robertson I, Jolles J. Effect of a structured course involving goal management training in older adults: A randomised controlled trial. Patient Educ Couns. 2007;65(2):205-13. [PMID:16956743]

http://dx.doi.org/10.1016/j.pec.2006.07.010

17. Alfonso JP, Caracuel A, Delgado-Pastor LC, VerdejoGarcía A. Combined Goal Management Training and Mindfulness meditation improve executive functions and decision-making performance in abstinent polysubstance abusers. Drug Alcohol Depend. 2011;117(1):78-81. [PMID:21277705] http://dx.doi.org/10.1016/j.drugalcdep.2010.12.025

18. Levine B, Stuss DT, Winocur G, Binns MA, Fahy L, Mandic M, Bridges K, Robertson IH. Cognitive rehabilitation in the elderly: Effects on strategic behavior in relation to goal management. J Int Neuropsychol Soc. 2007;13(1): 143-52. [PMID:17166313] http://dx.doi.org/10.1017/S1355617707070178

19. Manly T, Hawkins K, Evans J, Woldt K, Robertson IH. Rehabilitation of executive function: Facilitation of effective goal management on complex tasks using periodic auditory alerts. Neuropsychologia. 2002;40(3):271-81.

[PMID:11684160] http://dx.doi.org/10.1016/S0028-3932(01)00094-X

20. Sweeney S, Kersel D, Morris RG, Manly T, Evans JJ. The sensitivity of a virtual reality task to planning and prospective memory impairments: Group differences and the efficacy of periodic alerts on performance. Neuropsychol Rehabil. 2010;20(2):239-63. [PMID:19742380] http://dx.doi.org/10.1080/09602010903080531

21. Management of Concussion/mTBI Working Group. VA/ DoD Clinical Practice Guideline for Management of Concussion/Mild Traumatic Brain Injury. J Rehabil Res Dev. 2009;46(6):CP1-68. [PMID:20108447]

22. Nelson HE. W.J., National Adult Reading Test manual. Windsor (UK): NFER; 1991.

23. Taber KH, Warden DL, Hurley RA. Blast-related traumatic brain injury: What is known? J Neuropsychiatry Clin Neurosci. 2006;18(2):141-45. [PMID:16720789]

http://dx.doi.org/10.1176/jnp.2006.18.2.141

24. Todd JS, Johnson KH; American Medical Association Council on Ethical and Judicial Affairs. Annotated guidelines on gifts to physicians from industry. J Okla State Med Assoc. 1992;85(5):227-31. [PMID:1512644]

25. Tombaugh T. Test of memory malingering: TOMM. North Tonawanda (NY): Multi-Health Systems; 1996.

26. Kazdin A. Single-case research designs: Methods for clinical and applied settings. New York (NY): Oxford University Press; 1982.

27. Krishnan M, Smith N, Donders J. Use of the Tower of London-Drexel University, Second Edition (TOLDX) in adults with traumatic brain injury. Clin Neuropsychol, 2012;26(6): 951-64. [PMID:22849344]

28. Berg WK, Byrd DL, McNamara JP, Case K. Deconstructing the tower: Parameters and predictors of problem difficulty on the Tower of London task. Brain Cogn. 2010;72(3): 472-82. [PMID:20167413]

http://dx.doi.org/10.1016/j.bandc.2010.01.002

29. Unterrainer JM, Owen AM. Planning and problem solving: From neuropsychology to functional neuroimaging. J Physiol Paris. 2006;99(4-6):308-17. [PMID:16750617] http://dx.doi.org/10.1016/j.jphysparis.2006.03.014

30. Kaller CP, Unterrainer JM, Rahm B, Halsband U. The impact of problem structure on planning: Insights from the Tower of London task. Brain Res Cogn Brain Res. 2004; 20(3):462-72. [PMID:15268923]

http://dx.doi.org/10.1016/j.cogbrainres.2004.04.002

31. Kaller CP, Unterrainer JM, Stahl C. Assessing planning ability with the Tower of London task: Psychometric properties of a structurally balanced problem set. Psychol Assess. 2012;24(1):46-53. [PMID:21859218]

http://dx.doi.org/10.1037/a0025174

32. Stokes TF, Baer DM. An implicit technology of generalization. J Appl Behav Anal. 1977;10(2):349-67.

[PMID:16795561]

http://dx.doi.org/10.1901/jaba.1977.10-349

33. Roth RM, Isquith PK, Gioia GA. BRIEF-A: Behavior Rating Inventory of Executive Function-Adult Version. Lutz (FL): Psychological Assessment Resources; 2005.

34. Waid-Ebbs JK, Wen PS, Heaton SC, Donovan NJ, Velozo C. The item level psychometrics of the Behavior Rating Inventory of Executive Function-Adult (BRIEF-A) in a TBI sample. Brain Inj. 2012;26(13-14):1646-57.

[PMID:22876936]

http://dx.doi.org/10.3109/02699052.2012.700087

35. Unterrainer JM, Rahm B, Leonhart R, Ruff CC, Halsband $\mathrm{U}$. The Tower of London: The impact of instructions, cueing, and learning on planning abilities. Brain Res Cogn Brain Res. 2003;17(3):675-83. [PMID:14561454] http://dx.doi.org/10.1016/S0926-6410(03)00191-5

36. Spikman JM, Boelen DH, Lamberts KF, Brouwer WH, Fasotti L. Effects of a multifaceted treatment program for executive dysfunction after acquired brain injury on indications of executive functioning in daily life. J Int Neuropsychol Soc. 2010;16(1):118-29. [PMID:19900348] http://dx.doi.org/10.1017/S1355617709991020

37. Schweizer TA, Levine B, Rewilak D, O’Connor C, Turner G, Alexander MP, Cusimano M, Manly T, Robertson IH, Stuss DT. Rehabilitation of executive functioning after focal damage to the cerebellum. Neurorehabil Neural Repair. 2008;22(1):72-77. [PMID:17664355] http://dx.doi.org/10.1177/1545968307305303 
38. Keith Berg W, Byrd D. The Tower of London spatial problem-solving task: Enhancing clinical and research implementation. J Clin Exp Neuropsychol. 2002;24(5):586-604. [PMID:12187443]

http://dx.doi.org/10.1076/jcen.24.5.586.1006

39. Feldstein SN, Keller FR, Portman RE, Durham RL, Klebe KJ, Davis HP. A comparison of computerized and standard versions of the Wisconsin Card Sorting Test. Clin Neuropsychol. 1999;13(3):303-13. [PMID:10726602] http://dx.doi.org/10.1076/clin.13.3.303.1744

40. Williams D, Jarrold C. Assessing planning and set-shifting abilities in autism: Are experimenter-administered and computerised versions of tasks equivalent? Autism Res. 2013;6(6):461-67. [PMID:23893967] http://dx.doi.org/10.1002/aur.1311

41. Shum D, Gill H, Banks M, Maujean A, Griffin J, Ward H. Planning Ability Following moderate to severe traumatic brain injury: Performance on a 4-disk version of the Tower of London. Brain Impair. 2009;10(03):320-24. http://dx.doi.org/10.1375/brim.10.3.320

42. Goel V, Grafman J. Are the frontal lobes implicated in "planning" functions? Interpreting data from the Tower of Hanoi. Neuropsychologia. 1995;33(5):623-42. [PMID:7637857] http://dx.doi.org/10.1016/0028-3932(95)90866-P

43. Fish J, Evans JJ, Nimmo M, Martin E, Kersel D, Bateman A, Wilson BA, Manly T. Rehabilitation of executive dysfunction following brain injury: "content-free" cueing improves everyday prospective memory performance. Neuropsychologia. 2007;45(6):1318-30.

[PMID:17084422]

http://dx.doi.org/10.1016/j.neuropsychologia.2006.09.015

44. Metzler-Baddeley C, Jones RW. Brief communication: Cognitive rehabilitation of executive functioning in a case of craniopharyngioma. Appl Neuropsychol. 2010;17(4): 299-304. [PMID:21154044] http://dx.doi.org/10.1080/09084282.2010.523394

45. Boman IL, Lindstedt M, Hemmingsson H, Bartfai A. Cognitive training in home environment. Brain Inj. 2004; 18(10):985-95. [PMID:15370898] http://dx.doi.org/10.1080/02699050410001672396

46. Fisher AG. Assessment of motor and process skills. 2nd ed. Fort Collins (CO): Three Star Press; 1997.

47. Toglia J, Johnston MV, Goverover Y, Dain B. A multicontext approach to promoting transfer of strategy use and self regulation after brain injury: An exploratory study. Brain Inj. 2010;24(4):664-77. [PMID:20235769] http://dx.doi.org/10.3109/02699051003610474

48. Lange RT, Brickell TA, Kennedy JE, Bailie JM, Sills C, Asmussen S, Amador R, Dilay A, Ivins B, French LM.
Factors influencing postconcussion and posttraumatic stress symptom reporting following military-related concurrent polytrauma and traumatic brain injury. Arch Clin Neuropsychol. 2014;29(4):329-47. [PMID:24723461] http://dx.doi.org/10.1093/arclin/acu013

49. Koeler R, Wilhelm I, Shoulson I; Institute of Medicine Committee on Cognitive Rehabilitation Therapy for Traumatic Brain Injury. Cognitive rehabilitation therapy for traumatic brain injury. Washington (DC): National Academies Press; 2011.

50. Novakovic-Agopian T, Chen AJ, Rome S, Abrams G, Castelli H, Rossi A, McKim R, Hills N, D’Esposito M. Rehabilitation of executive functioning with training in attention regulation applied to individually defined goals: A pilot study bridging theory, assessment, and treatment. J Head Trauma Rehabil. 2011;26(5):325-38. [PMID:21169860] http://dx.doi.org/10.1097/HTR.0b013e3181f1ead2

51. Logan GD, Schachar RJ, Tannock R. Impulsivity and inhibitory control. Psychol Sci. 1997;8:60-64. http://dx.doi.org/10.1111/j.1467-9280.1997.tb00545.x

52. Sütterlin S, Herbert C, Schmitt M, Kübler A, Vögele C. Frames, decisions, and cardiac-autonomic control. Soc Neurosci. 2011;6(2):169-77. [PMID:20661838] http://dx.doi.org/10.1080/17470919.2010.495883

53. Kramer JH, Mungas D, Possin KL, Rankin KP, Boxer AL, Rosen HJ, Bostrom A, Sinha L, Berhel A, Widmeyer M. NIH EXAMINER: Conceptualization and development of an executive function battery. J Int Neuropsychol Soc. 2014;20(1):11-19. [PMID:24103232]

Submitted for publication February 14, 2014. Accepted in revised form November 3, 2014.

This article and any supplementary material should be cited as follows:

Waid-Ebbs JK, Daly J, Wu SS, Berg WK, Bauer RM, Perlstein WM, Crosson B. Response to Goal Management Training in Veterans with blast-related mild traumatic brain injury. J Rehabil Res Dev. 2014;51(10): 1555-66.

http://dx.doi.org/10.1682/JRRD.2013.12.0266

ResearcherID/ORCID: J. Kay Waid-Ebbs, PhD, BCBAD: H-90604-2012; Bruce Crosson, PhD: L-3128-2013

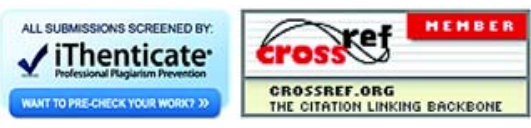

